$006-007$

Noticias

y comentarios

PH44 - Julio 2003

\title{
Arquitectura contemporánea de calidad para afrontar los desafíos del futuro museo de Jaén
}

Una de las principales controversias surgidas en los últimos meses, en la ciudad de Jaén, ha sido la propuesta de construcción de un nuevo museo en el recinto de la antigua prisión provincial. Diversas voces han planteado cuál debe ser el modelo a seguir por el nuevo museo, a la vez que aparece la polémica sobre el mantenimiento del viejo edificio de la prisión o su demolición. En esta encrucijada se han mezclado conflictos corporativos, políticos y competenciales que han dificultado la compresión integral y ordenada del problema.

La Fundación Arquitectura Contemporánea, que nace con el objetivo de actuar como catalizador en la difusión, promoción e investigación de la arquitectura y ciudad contemporáneas, ha querido organizar junto con la Consejería de Cultura, su primera actividad pública en la ciudad de Jaén con la pretensión de aportar ideas y contribuir de forma positiva al debate existente sobre el tipo de museo que la ciudad necesita.

Las Jornadas, bajo el título "Arquitectura de los museos" (Jaén, 27 y 28 de marzo de 2003), se desarrollaron conforme el programa previsto. Declarándose más cerca de las preguntas que de las respuestas, el filósofo Francisco Jarauta inició las intervenciones con una brillante conferencia en la que desarrolló la idea de museo, ciudad y arquitectura como tres conceptos indisolubles e inseparables entre sí. Las intervenciones que siguieron consistieron en arquitectos autores de proyectos y edificios de museos; comenzó Alfredo Payá mostrando el Museo Universitario de Alicante y continuó las exposiciones el arquitecto Heinrich Degelo -del estudio suizo Morger \& Degelo-, que mostró el museo de la música de Basilea realizado sobre una antigua prisión, el museo de arte de Vaduz y el concurso para un museo en Alemania, demostrando que la arquitectura contemporánea puede intervenir en contextos históricos diversos. Antonio Ortiz, del estudio Cruz \& Ortiz, expuso su propuesta ganadora en el concurso para la remodelación del Rijksmuseum de Ámsterdam y por último, el equipo de Ignacio García Pedrosa y Ángela García de Paredes describió su propuesta de ampliación para el Landesmuseum de Zürich y el nuevo museo arqueológico de Almería, próximo a concluir y pendiente del proyecto museográfico.

La calidad de los museos mostrados, unos realizados en edificios rehabilitados, otros en edificios de nueva planta, hizo evidente lo ficticio o interesado de la polémica sobre la demolición o mantenimiento de la antigua prisión de Jaén, ya que en ambos casos es posible la buena arquitectura que una ciudad espera y desea para sus edificios. Sin embargo, antes de plantear cómo ha de ser el continente de un museo es esencial definir el contenido o qué tipo de museo se quiere, porque para realizar un buen proyecto es necesario no sólo un buen arquitecto sino un interlocutor que cuando sabe lo que quiere, encuentra lo que busca y como consecuencia hará siempre posible la arquitectura.

En la mesa redonda se plantearon las nuevas necesidades y cuestiones que presenta la construcción de un nuevo museo en el contexto de la ciudad de Jaén.

Desde diferentes puntos de vista se planteó la consideración relativa que tienen los inmuebles de un centro urbano. Los valores de un edificio son aquellos que les otorga la propia ciudad en donde se ubican; no existe un escalafón de categorías absolutas ordenadas en términos históricos, artísticos o arquitectónicos. En este valor que cada ciudad le da a su conjunto edificado, tienen mucha importancia las escalas. No sólo la Catedral, el Castillo o los Baños Árabes merecen la pena en Jaén, sino también sus calles, sus ambientes, sus paisajes, etc.

Sin embargo parece que la ciudad, en los últimos años, ha asumido con una natural indiferencia los procesos de alteración de su conjunto edificado: la sencillez y sobriedad de su arquitectura tradicional ha servido de excusa para operaciones en las que "como nada vale, todo vale". Un cierto complejo de autoestima en relación a otras ciudades andaluzas ha sido hábilmente utilizado para poder actuar sin ningún reparo, ni escrúpulo en toda la ciudad. Dentro de las diversas escalas que tiene la ciudad, se sitúa la arquitectura del siglo veinte, una arquitectura que se ha demostrado muy frágil. Recordemos las demoliciones del teatro Cervantes, de la antigua Maternidad y podemos adivinar las previstas en la Escuela de Peritos, las Protegidas y la Estación de Autobuses.

La demolición, como recordaba Hernández de León (Escuela de Arquitectura de Madrid), tiene el mismo carácter que la pena de muerte, es decir, es irreversible. En este contexto es donde la posición de algunos intervinientes justifica la conservación de un edificio como la antigua prisión, integrándola en la solución final del museo. Aún asumiendo las dificultades que conlleva la transformación simbólica de un espacio de represión en un espacio de libertad, siempre es posible realizar una arquitectura de calidad, plenamente actual y contemporánea, modificando la arquitectura existente, testigo mudo de la historia.

El profesor Arturo Ruiz (Centro de Arqueología Ibérica) mantuvo que, asumiendo la necesidad de descomponer las secciones del actual museo, 
Jaén tiene la oportunidad de unir a través del Paseo de la Estación, en un recorrido que iría de Norte a Sur, las tres ciudades que la han conformado: la macro aldea calcolítica de Marroquies Bajos, la ciudad moderna y la ciudad medieval. Una especie de bucle urbano que estaría centrado en el futuro Museo de Jaén, casa depositaria de la antigua memoria de la ciudad y que albergaría uno de los mayores valores emergentes de la provincia: el arte y la cultura Ibera.

Las reflexiones de las jornadas han intentado mostrar cómo la arquitectura contemporánea de calidad constituye el único modo de afrontar los desafíos que las instituciones museisticas reclaman en la sociedad actual. Esperemos que la re- ciente convocatoria del concurso internacional de ideas, realizada por la Consejería de Cultura, para la construcción del Museo Internacional de Arqueología y Arte Ibérico de Jaén, sea atractiva para los buenos profesionales, tenga un jurado de prestigio, cualificado e independiente y que la propuesta premiada de una respuesta adecuada a las demandas de la sociedad jiennense.

\section{Santiago Quesada}

Patronato Fundación Arquitectura

Contemporánea

\section{Un Plan de Calidad para los Museos Andaluces}

La Dirección General de Instituciones del Patrimonio Histórico (Consejeria de Cultura, Junta de Andalucía) acaba de publicar el avance sobre este trabajo que pretende abordar la modernización de los museos de la región, para la mejora de la calidad de sus programas y contenidos

El documento, elaborado a partir del consenso de los principales agentes que intervienen en el museo como institución cultural, espera las aportaciones y sugerencias de todos aquellos profesionales, instituciones, colectivos y sociedad en general que deseen participar en su mejora. El texto completo puede ser consultado en: www.juntadeandalucia.es/cultura/

El museo Zumalakarregi muestra el s. XIX a través de un juego interactivo

Acceso:

www.gipuzkoakultura.net/museos/zm/juego.htm

Más información:

Museo Zumalakarregi (Guipúzcoa)

Tel.: 943889900

mzumalakarregi@kultura.gipuzkoa.net

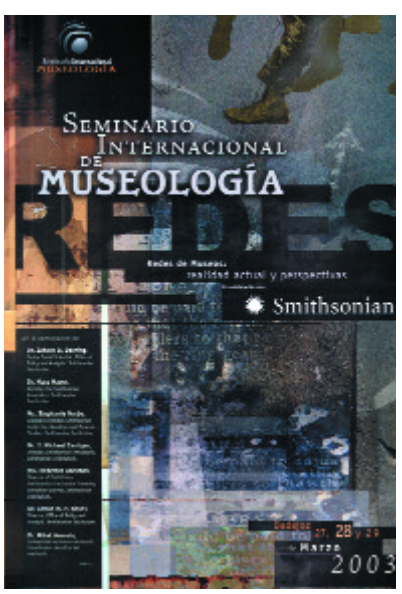

\section{Extremadura pretende consolidar un foro internacional sobre redes de museos}

Conocer los proyectos en marcha de redes de museos y analizar los diferentes casos de funcionamiento en redes que, si bien aportan una mejor adaptación a muchos de los problemas de los museos actuales, también generan nuevos retos y dificultades, fueron los objetivos del Seminario Internacional de Museología "REDES de Museos: Realidad actual y perspectivas". El encuentro, sin precedentes en nuestro país, tuvo lugar los días 27, 28 y 29 de marzo en el Museo Extremeño e Iberoamericano de Arte Contemporáneo, y fue organizado por la Consejería de Cultura de la Junta de Extremadura, con la colaboración de la Smithsonian Institution.

Durante las tres jornadas que duró el seminario, más de un centenar de participantes tuvieron la oportunidad de contactar y debatir acerca de las disfunciones y tensiones que comporta todo cambio estructural en las instituciones. Se señaló especialmente que las estructuras de las redes de los museos, que afectan a todas las funciones de los centros, deberían reunir dos condiciones: ser estructuras flexibles y tener acciones concretas y a corto plazo, con el fin de que no se queden en una declaración de intenciones.

Con este seminario, la Red de Museos de Extremadura ha logrado un espacio de reflexión, en un momento en que las redes de museos de España comienzan a convertirse en una realidad. Los expertos nacionales e internacionales en gestión de museos coincidieron en la necesidad de consolidar el encuentro como un foro internacional de intercambio de información y experiencias entre las redes de museos. 